Mongolian Academy of Sciences
Mongolian Journal of Chemistry
Institute of Chemistry \& Chemical Technology

\title{
Gas Sensing Performance of Multiple-shell Hollow Silver and Hematite Composite Microspheres
}

\author{
Garnaad Ariunaa ${ }^{1}$, Gunchin Burmaa ${ }^{1}$, Xiaoyong Lai $^{2}$, Dan Wang ${ }^{2}$, \\ ${ }^{1}$ Institute of Chemistry and Chemical Technology, MAS, Ulaanbaatar 13330, Mongolia, \\ ${ }^{2}$ Institute of Process Engineering, CAS, Beijing100190, China
}

\begin{abstract}
In this report, multiple-shell hollow silver and hematite composite microsphere has been prepared by using carbonaceous saccharide microsphere as template. The products were characterized by X-ray powder diffraction (XRD), scanning electronic microscopy (SEM), transmission electron microscopy (TEM), and energy dispersive X-ray spectroscopy (EDX). The core size and shell thickness of hollow spheres obtained can be manipulated by changing the concentration of metal salt. The unique multiple-shell hollow silver and hematite composite microspheres may be potentially used as gas-sensor materials for detecting various toxic gases.
\end{abstract}

Keywords: Carbonaceous saccharide, Template, $\mathrm{Ag} / \alpha-\mathrm{Fe}_{2} \mathrm{O}_{3}$, Sensitivity

\section{Introduction}

$\mathrm{H}$ ollow spheres with nanometer to micrometer dimensions, defined composition, controlled interior structure and tunable shell numbers have attracted tremendous attention because of their potential applications in catalysis, drug storage and controlled release, nanoreactors, photonic devices, sensor, and biotechnology, and so on ${ }^{1-6}$. Most of single shelled hollow spheres have been synthesized by template assisted synthesis or other methods ${ }^{2}$. Double shelled hollow spheres could be obtained by using sulfonated hollow sphere as template ${ }^{7,8}$ or the layer-by-layer templating technique. Furthermore, considerable effort has been devoted to fabricate hollow spheres with higher-level interior structure (such as multishell or multi-chamber), which are expected to provide more advantages in drug release with prolonged release time, in heterogeneous catalysis, and in $\mathrm{Li}$ ion batteries etc ${ }^{8}$. Very recently, they further extended this method to prepare metal oxide hollow microspheres with multiple shells and found that those multi-shelled hollow microspheres possessed very unique sensing properties, whose response significantly increases with their numbers of shells.

Herein, we have attempted to prepare multiple shell hollow $\mathrm{Ag} / \alpha-\mathrm{Fe}_{2} \mathrm{O}_{3}$ composite sphere by carbonaceous microspheres as template and silver nitrate and iron nitrate solutions as precursors. We investigated the effect of various experimental parameters on the morphologies and phase of the resultant products, such as the concentration and $\mathrm{pH}$ value of solution and the ratio of silver and 
iron ions. The resultant multiple shell hollow $\mathrm{Ag} / \alpha-\mathrm{Fe}_{2} \mathrm{O}_{3}$ composite microspheres are expected to have improved performance over those of multiple shell hollow $\alpha-\mathrm{Fe}_{2} \mathrm{O}_{3}$ composite microspheres.

\section{Experimental}

\section{Preparation of carbonaceous microspheres.}

Carbonaceous saccharide microspheres were synthesized through the emulsion polymerization reaction of sugar under hydrothermal conditions as described elsewhere $^{1}$. Was dissolved $205 \mathrm{~g}$ of Sucrose in $300 \mathrm{ml}$ of water to form a clear solution, which was placed into a $1000 \mathrm{ml}$ Teflonsealed autoclave, heated and maintained at $200^{\circ} \mathrm{C}$ for some time ( 3 hours and 32 minutes $\sim 3$ hours and 38 minutes). The black or puce products was filtered and washed with distilled water and absolute ethanol, and finally dried under vacuum at $80^{\circ} \mathrm{C}$ for 12 hours.

\section{Preparation of multiple shell hollow $\alpha-\mathrm{Fe}_{2} \mathrm{O}_{3}$ microspheres.}

In typical synthesis, $0.6 \mathrm{~g}$ carbon microsphere was added into $50 \mathrm{ml}$ of iron nitrate ethanol solution (2, 3 and 4M), stirred for 6 hours and then filtered. The resultant products were washed with distilled water and absolute ethanol and finally dried under vacuum at $80^{\circ} \mathrm{C}$ for $12 \mathrm{~h}$. The as-prepared products were collected and heated to $500^{\circ} \mathrm{C}$ at the rate of $2^{0} \mathrm{C} / \mathrm{min}$ and maintained the temperature for $1 \mathrm{~h}$.

\section{Preparation of multiple shell hollow Ag/a-} $\mathrm{Fe}_{2} \mathrm{O}_{3}$ composite microsphere by wet chemical method.

Multiple shell hollow $\mathrm{Ag} / \alpha-\mathrm{Fe}_{2} \mathrm{O}_{3}$ composite microsphere were made by the wet chemical method, as described below. In a typical procedure, $20 \mathrm{ml}$ of $\mathrm{AgNO}_{3}$ solution (0.17, 0.23 and $1.17 \mathrm{M}$ ) was prepared in conical flask. And then $10 \mathrm{mg}$ of multiple shell hollow $\alpha-\mathrm{Fe}_{2} \mathrm{O}_{3}$ composite microsphere and
$1 \mathrm{~g}$ L-AA were added into the above mentioned solution and the mixed solution was heated to $60^{\circ} \mathrm{C}$ for $15 \mathrm{~min}$ under continuous stirring. The red products were collected by centrifugation and washed with distilled water and absolute ethanol in turn, finally dried under vacuum at $80^{\circ} \mathrm{C}$ for 12 hrs. The as-prepared products were collected and heated in air to $500^{\circ} \mathrm{C}$ at the rate of $2^{0} \mathrm{C} / \mathrm{min}$ and maintained the temperature for 1h. These as-prepared samples were characterized by XRD, scanning electron microscope (SEM), TEM, element analysis (EDX) $\left\{\mathrm{S}_{1}, \mathrm{~S}_{2}, \mathrm{~S}_{3}, \mathrm{~S}_{4}\right\}$.

Preparation of multiple shell hollow Ag/a$\mathrm{Fe}_{2} \mathrm{O}_{3}$ composite microsphere by the postdeposition method.

In a typical procedure, $20 \mathrm{ml}$ of $\mathrm{AgNO}_{3}$ solution $(0.17,0.23$ and $1.17 \mathrm{M})$ was prepared in conical flask. And then $10 \mathrm{mg}$ of multipleshell hollow $\alpha-\mathrm{Fe}_{2} \mathrm{O}_{3}$ composite microsphere the products were collected and washed with distilled water and absolute ethanol, finally dried under vacuum at $80^{\circ} \mathrm{C}$ for $12 \mathrm{hrs}$. The as-prepared products were collected and heated in air to $450^{\circ} \mathrm{C}$ at the rate of $2^{\circ} \mathrm{C} / \mathrm{min}$ and maintained the temperature for $2 \mathrm{hrs}$. $\left\{\mathrm{S}_{5}\right.$, $\left.\mathrm{S}_{6}, \mathrm{~S}_{7}\right\}$

Preparation of multiple shell hollow Ag/a$\mathrm{Fe}_{2} \mathrm{O}_{3}$ composite microsphere by the coprecipitation method.

In the typical synthesis, $0.6 \mathrm{~g}$ carbon microspheres were added into $50 \mathrm{ml}$ of the mixed solution of iron nitrate $(1.5,2,2.5$ and $3 \mathrm{M})$ and sliver nitrate $(0.002,0.006,0.01$, $0.02,0.03,0.1,0.15$ and $0.23 \mathrm{M})$ and stirring for $6 \mathrm{hrs}$ in the room temperature. The products were collected and washed with distilled water and absolute ethanol, finally dried under vacuum at $80^{\circ \mathrm{C}}$ for $12 \mathrm{hrs}$. The asprepared products were collected and heated in air to $500^{\circ} \mathrm{C}$ at the rate of $2^{\circ} \mathrm{C} / \mathrm{min}$ and maintained the temperature for $2 \mathrm{hrs}$. 
$\mathrm{AgNO}_{3}+2 \mathrm{Fe}\left(\mathrm{NO}_{3}\right)_{3} \stackrel{\text { Heat }}{\longrightarrow} \mathrm{Ag} / \alpha-\mathrm{Fe}_{2} \mathrm{O}_{3}+7 \mathrm{NO}_{2} \uparrow+4 \mathrm{O}_{2} \uparrow$

\section{Results and Discussion}

In typical SEM micrographs of carbonaceous saccharide microsphere templates was shown in Figure 1. The size of microsphere templates obtained at reaction time of 3 hours and 32 minutes was $2.6 \pm 0.2 \mu \mathrm{m}$, whereas those obtained at reaction time of 3 hours and 38 minutes was $2.45 \pm 0.2 \mu \mathrm{m}$. The surface of microsphere template is hydrophilic and has a distribution of $\mathrm{OH}$ and $\mathrm{C}=\mathrm{O}$ groups, which will favor the absorption of the template for cationic metal ions. Zeta potential analysis indicated that the surface of the microsphere templates was negatively charged in water $(\mathrm{pH}=4.5, \zeta=-47 \mathrm{eV})$.

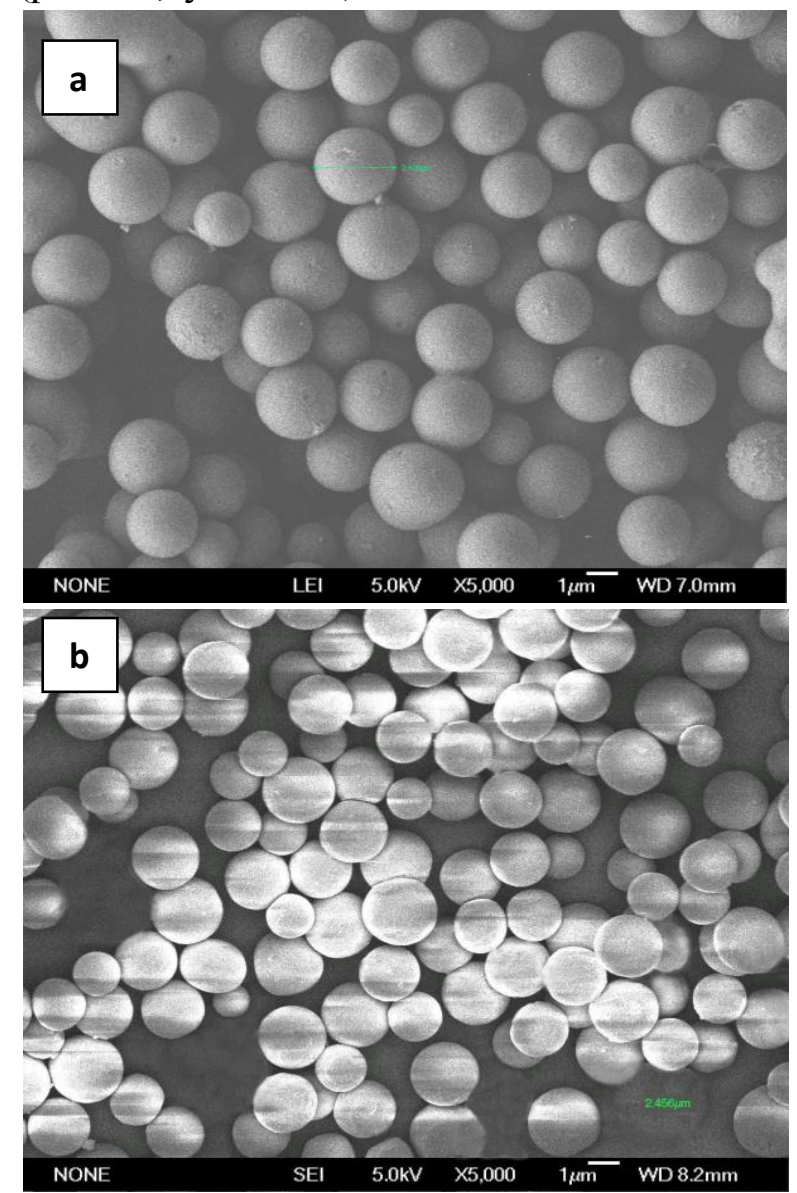

Figure1. SEM images of carbonaceous saccharide microsphere templates obtained at different reaction time: (a) $3 \mathrm{~h} 32$ and (b) $3 \mathrm{~h} 38$

Figure 2 shows the SEM images of $\mathrm{Fe}_{2} \mathrm{O}_{3}$ hollow microshperes. From the SEM images of $\mathrm{Fe}_{2} \mathrm{O}_{3}$ hollow spheres prepared at low metal-ions concentration (2M) are shown in
Figure 2a. The surface of the hollow sphere prepared at this condition is coarse and broken. Figure $2 \mathrm{~b}$ shows the overall morphology of hollow spheres synthesized at the condition of $3 \mathrm{M}$ and we noted that most hollow spheres had a small opening which might be the imprint from the template removal. Because the shells of the hollow spheres were very thin, we could observe some wrinkles on the hollow spheres. When the concentration of metal ions were raised to $C_{F e}=4 \mathrm{M}$, (figure $2 \mathrm{c}$ ) the surfaces became more smooth, which may be caused by the increase of shell thickness.
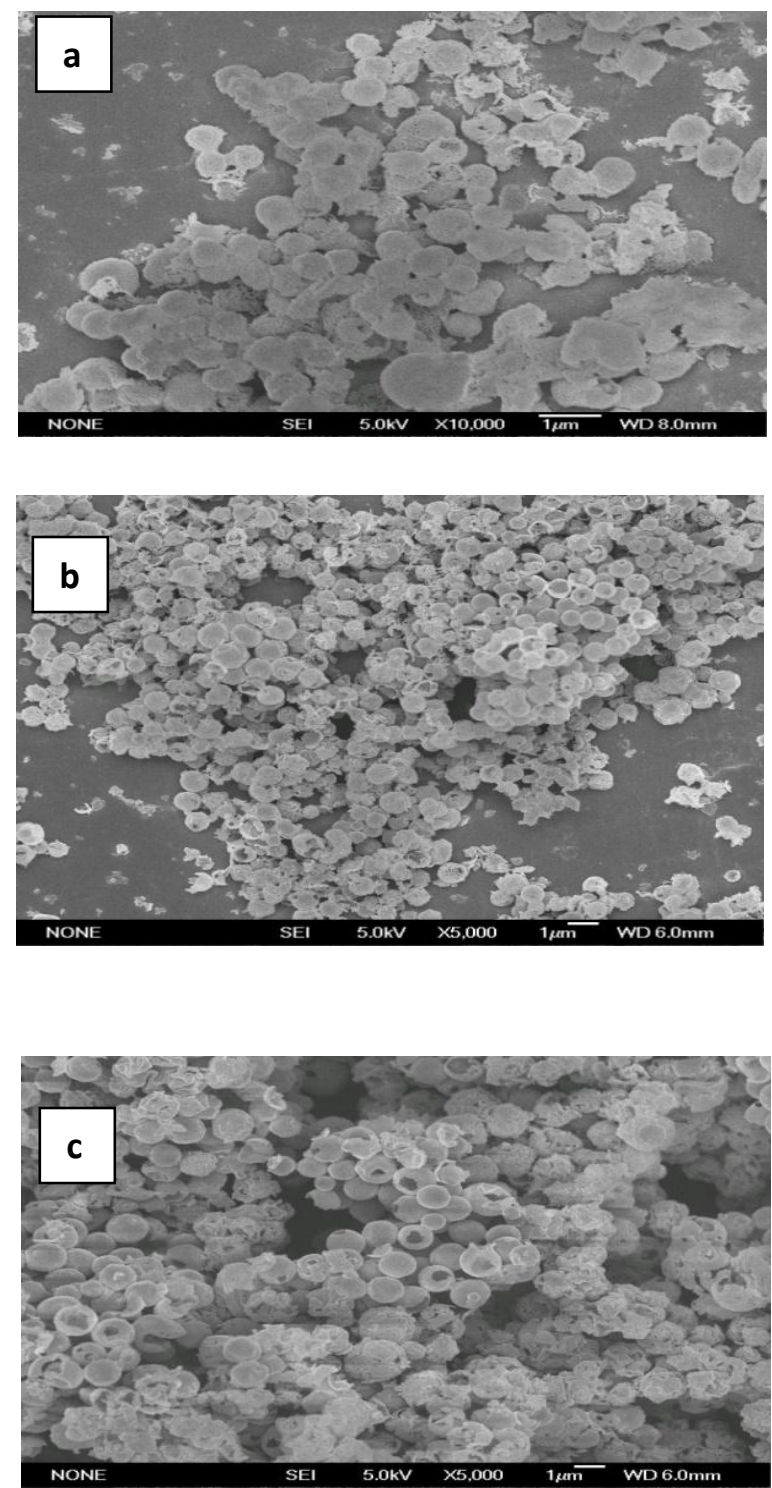

Figure 2. SEM images of $\mathrm{Fe}_{2} \mathrm{O}_{3}$ hollow microspheres byusing iron nitrate solution precursors with different concentration: (a) 2M, (b) $3 \mathrm{M}$ and (c) 4 M. 
This implies that more metal ions were absorbed into the templates. Moreover, we also found that there existed a small core in the inside of some broken spheres of products obtained at higher concentration of metal salts, which indicated these products may possess a hollow core-shell structure. The size of the resultant hollow spheres $(1.4 \pm 0.1 \mu \mathrm{m})$ is reduced to about $46 \%$ of the original size of template spheres, similar to that of single metal oxide hollow sphere (about 30\%). This reduction mainly depends on the shrinkage of template sphere due to further carbonization of organic matters and the densification of adsorbed metal ions to form oxides during the thermal treatment.We have prepared hematite hollow microspheres by using iron nitrate solution with concentration of 2 or $3 \mathrm{M}$ via hard templating method.

And then silver was deposited on the surface of hematite hollow microspheres by silver nitrate as precursor and LAA as reduced agents via wet chemical method. Figure 3 shows the SEM images of products with different silver amounts, which exhibits different morphologies. The corresponding EDX results exhibit that the ratio of silver and iron in the four products are 1/200, 1/209, $1 / 251$ and 4/1, respectively. The results suggest the amount of silver in the products increases with the concentration of silver nitrate solution used here. But here hollow microshpere was not formed.
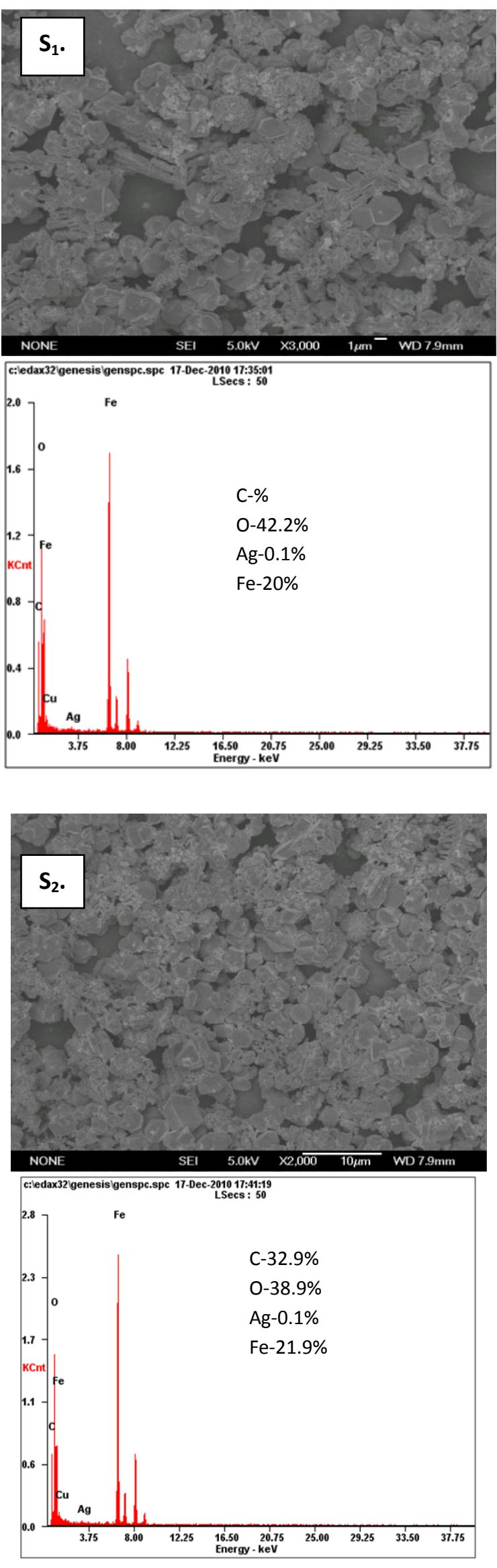

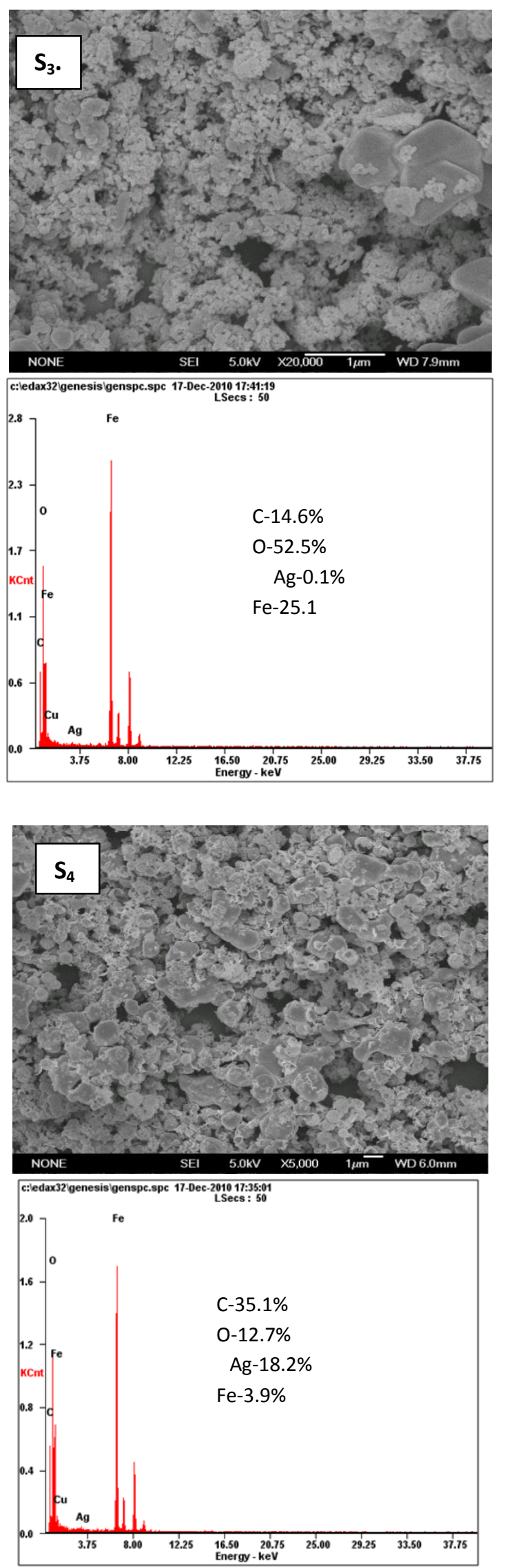

Figure 3. Scanning electron microscopy (SEM), EDX images of the synthesized silver doped iron oxide hollow sphere with different silver nitrate.
$\left.\mathrm{S}_{1}\right), 2 \mathrm{M}_{\mathrm{Fe} 203}$ at $\left.0.17 \mathrm{M}_{\mathrm{AgN} 03} \mathrm{~S}_{2}\right), 2 \mathrm{M}_{\mathrm{Fe} 203}$ at $0.23 \mathrm{M}_{\mathrm{AgN} 03}$, $\left.\mathrm{S}_{3}\right), 3 \mathrm{M}_{\mathrm{Fe} 203}$ at $\left.0.23 \mathrm{M}_{\mathrm{AgN} 03}, \mathrm{~S}_{4}\right), 3 \mathrm{M}_{\mathrm{Fe} 203}$ at $1.17 \mathrm{M}_{\mathrm{AgN} 03}$

Therefore, silver was deposited on the surface of hematite hollow microspheres by sliver nitrate as precursor and then heated at $450^{\circ} \mathrm{C}$ for 2 hours by post-deposition method. Figure 4 shows the SEM images of products with different silver amounts, which exhibits spherical morphologies and 1.6 2 $\mu \mathrm{m}$ in diameter. The XRD results only shows some diffraction peaks attributed to hematite and no peak of metal silver appears, which suggests the amount of silver in the products is possibly very few.
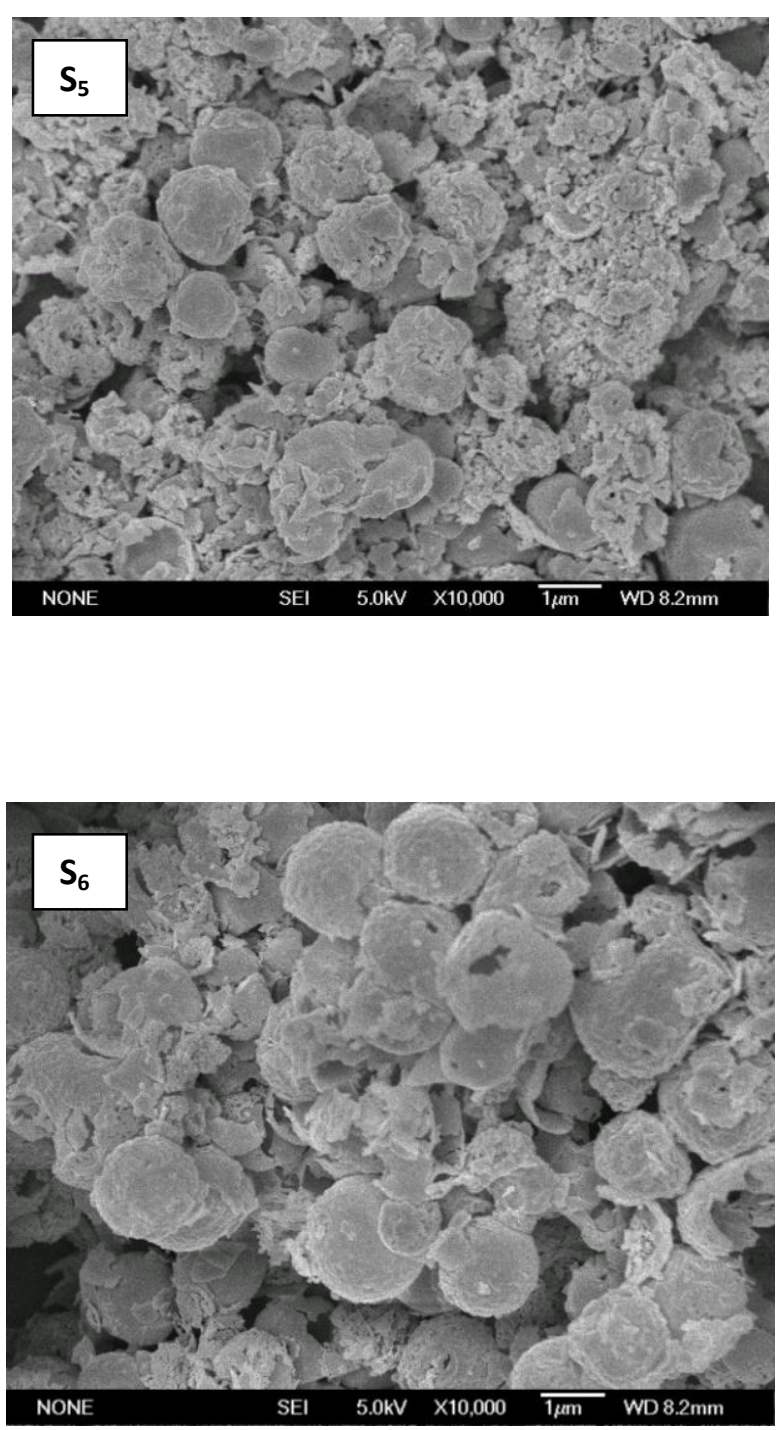


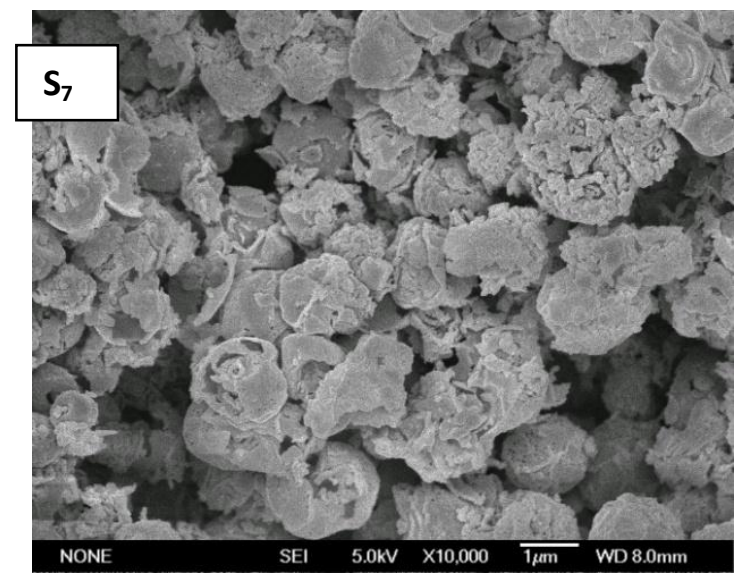

Figure 4. SEM images and XRD patterns of hollow composite microspheres obtained by using silver nitrate solutions with different concentration.

$$
\left.\left.\left.\mathrm{S}_{5}\right), 2 \mathrm{M}_{\mathrm{Fe}} \text { at } 0.1 \mathrm{M}_{\mathrm{AgN} 03} \mathrm{~S}_{6}\right), 4 \mathrm{M}_{\mathrm{Fe}} \text { at } 0.01 \mathrm{M}_{\mathrm{AgN} 03}, \mathrm{~S}_{7}\right) \text {, }
$$$$
4 \mathrm{M}_{\mathrm{Fe}} \text { at } 0.1 \mathrm{M}_{\mathrm{AgN} 03} \text {. }
$$

We used $0.6 \mathrm{~g}$ carbon microspheres as template and the mixed solution of iron nitrate $(1.5,2,2.5$ and $3 \mathrm{M})$ and sliver nitrate (0.002, 0.006, 0.01, 0.02, 0.03, 0.1, 0.15 and $0.23 \mathrm{M})$ as precursors to prepare composite hollow microspheres via co-precipitation method.
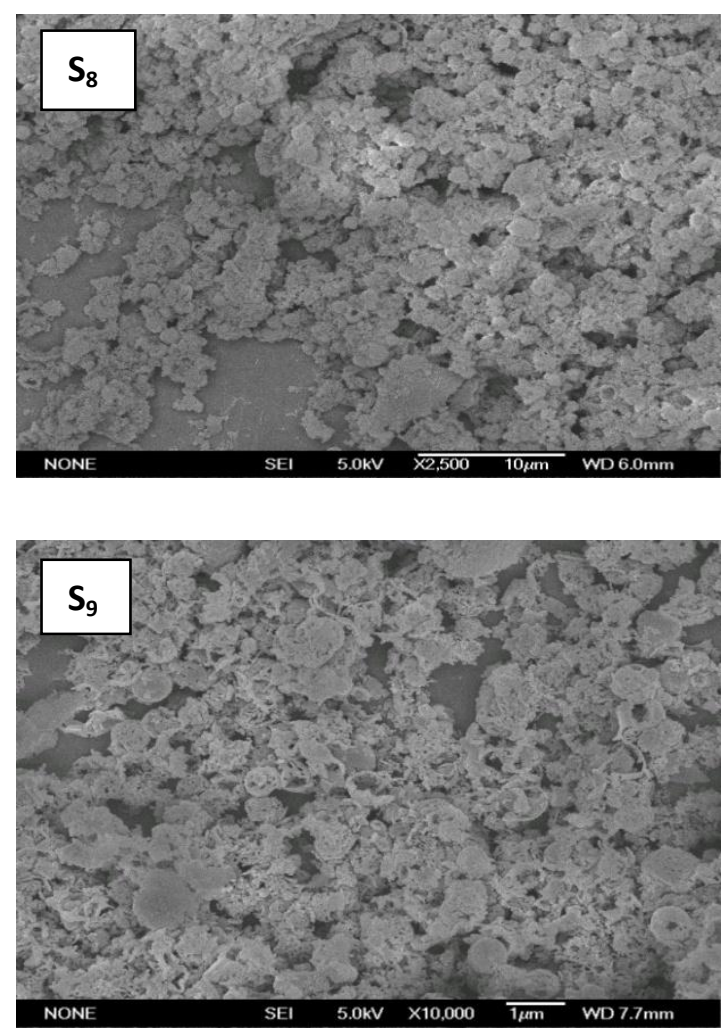

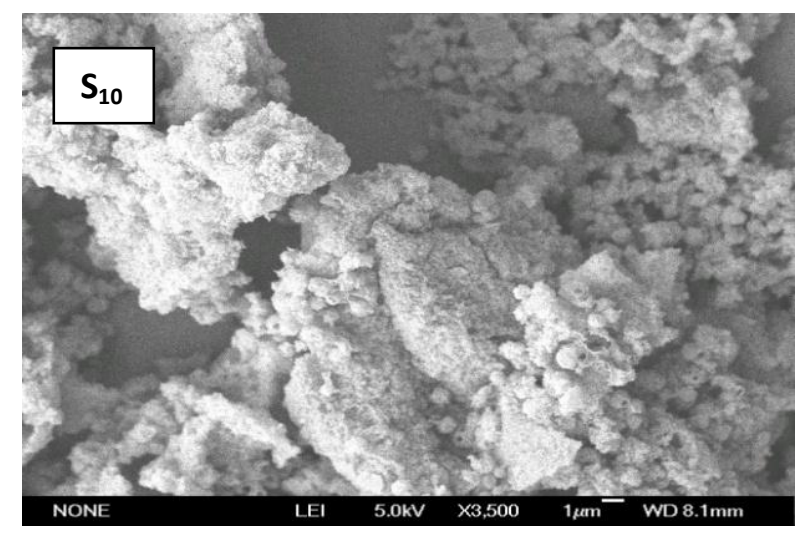

Figure 5. Scanning electron microscopy (SEM), images of the synthesized hollow composite microspheres obtained by using silver nitrate solutions with different concentration.

$\left.\mathrm{S}_{8}\right), 1.5 \mathrm{M}_{\mathrm{Fe}}$ at $0.03 \mathrm{M}_{\mathrm{AgN} 03}\left(\mathrm{~S}_{9}\right), 2 \mathrm{M}_{\mathrm{Fe}}$ at $0.02 \mathrm{M}_{\mathrm{AgN} 03}$, $\mathrm{S}_{10)}, 2.5 \mathrm{M}_{\mathrm{Fe}}$ at $0.23 \mathrm{M}_{\mathrm{AgN} 03}$.

When iron nitrates solution with low concentration (1.5-2.5 M) were used, the resultant product are some broken hollow microspheres (see Figure 5), which could be attribute that the introduction of silver ions affected the absorption of irons ions on the carbonaceous microsphere templates and resulted in a low absorbing amount of iron ions and thinner hematite shell. We increased the concentration of iron nitrate solution to $3 \mathrm{M}$. SEM images of the resulting products $\left(\mathrm{S}_{11}, \mathrm{~S}_{12}, \mathrm{~S}_{13}\right)$ were shown in Figure 6. It can be seen that the integrity of the resultant products were significantly improved.

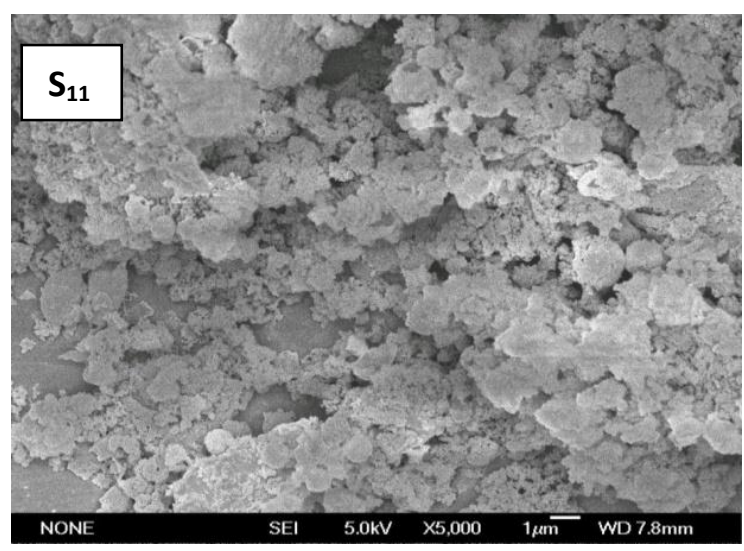



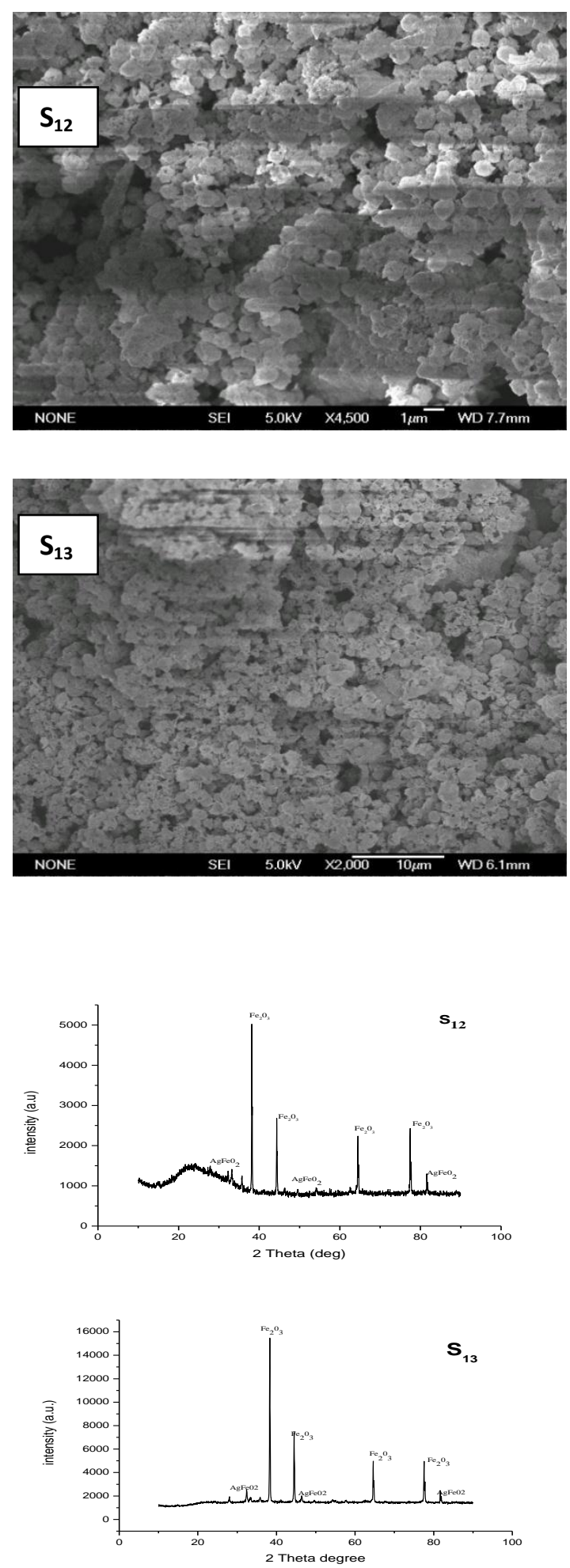

Figure 6. Scanning electron microscopy (SEM), XRD images of the synthesized hollow silver and iron oxide composite microspheres obtained by using silver nitrate solutions with different concentration.

$\left.\mathrm{S}_{11}\right), 3 \mathrm{M}_{\mathrm{Fe}}$ at $\left.0.15 \mathrm{M}_{\mathrm{AgN} 03} \mathrm{~S}_{12}\right), 3 \mathrm{M}_{\mathrm{Fe}}$ at $0.23 \mathrm{M}_{\mathrm{AgN} 03}, \mathrm{~S}_{13}$ ), $3 \mathrm{M}_{\mathrm{Fe}}$ at $0.05 \mathrm{M}_{\mathrm{AgN} 03}$.
More microspheres would be observed from the SEM images (Figure 6). Furthermore, we decreased the concentration of silver nitrate solution for avoiding the affection of silver on the adsorption of iron ions over carbonaceous microsphere templates.

SEM images of the resulting products $\left(\mathrm{S}_{14}\right.$, $\mathrm{S}_{15}, \mathrm{~S}_{16}, \mathrm{~S}_{17}$ ) were shown in Figure 7 , which confirmed our speculation.
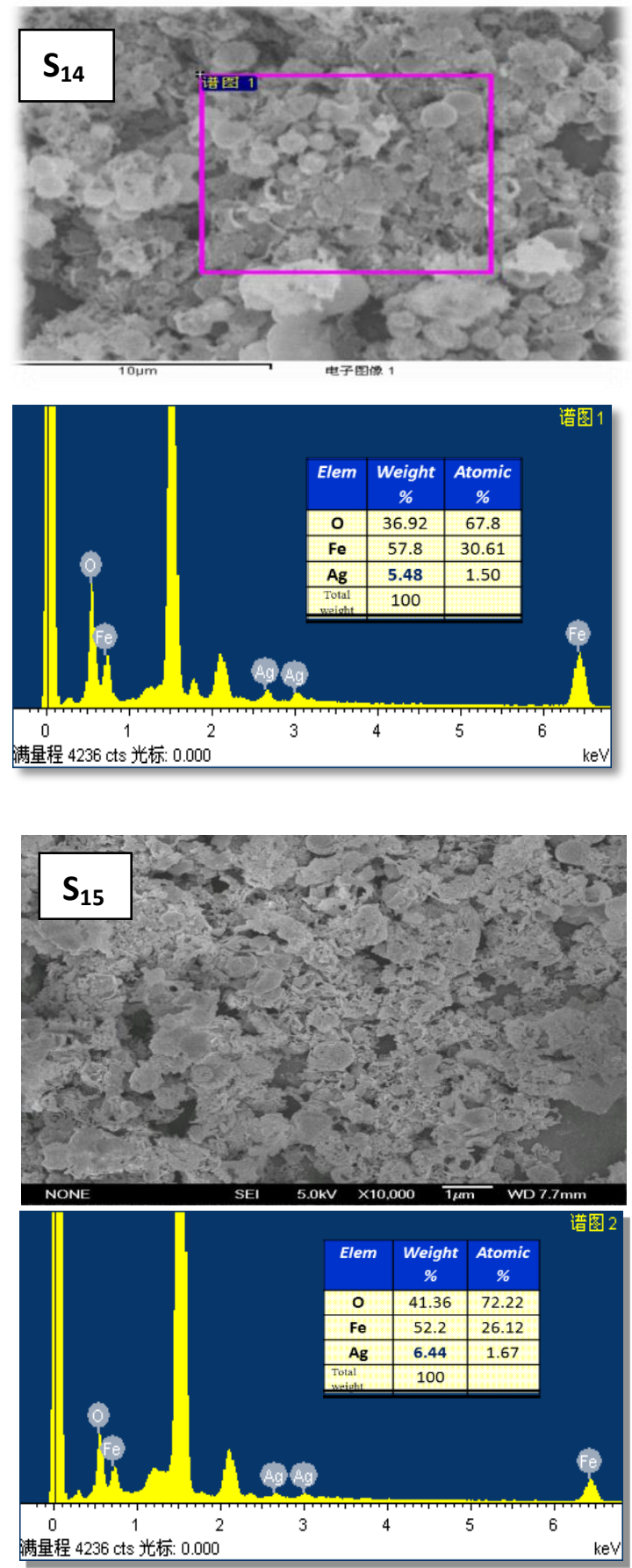

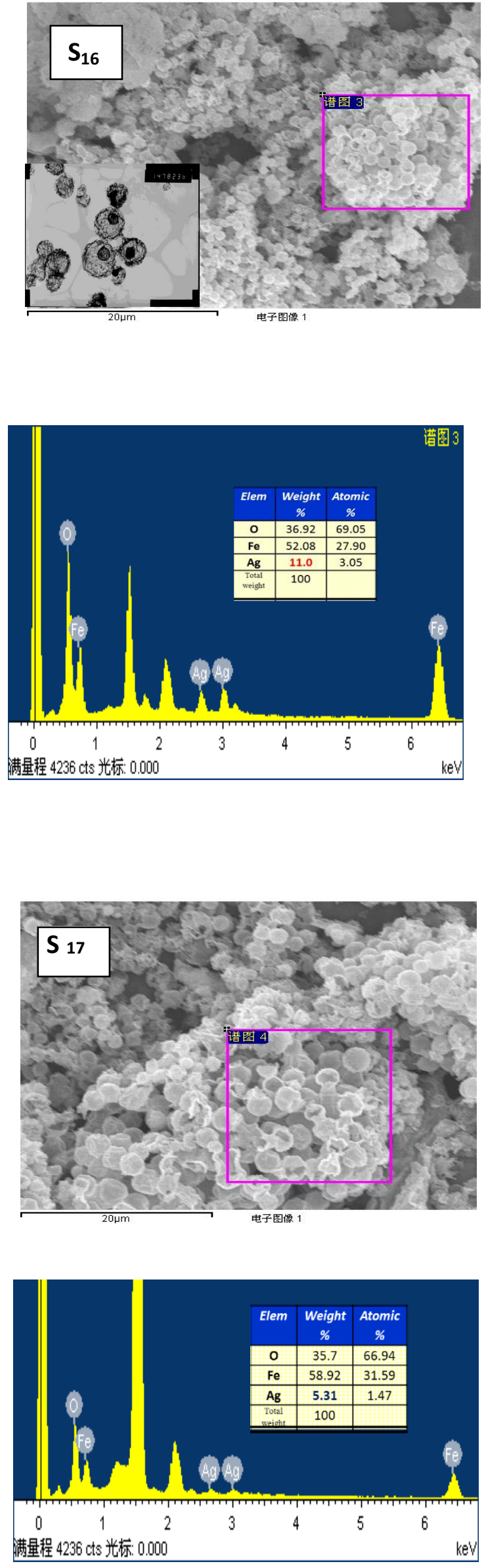

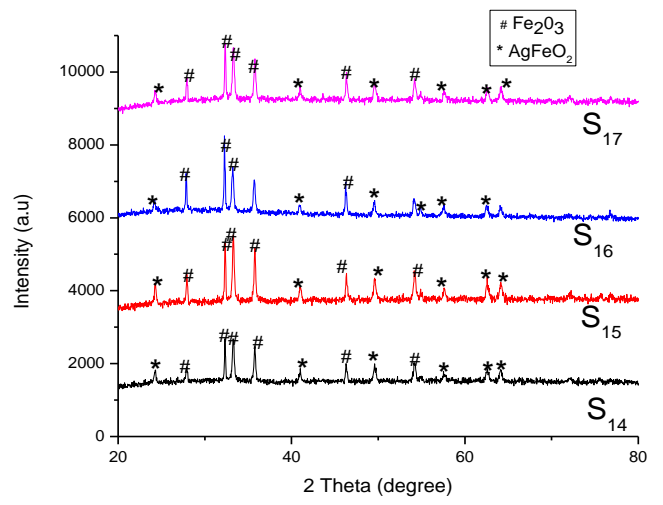

Figure 7. SEM and TEM images, XRD and EDX patterns of the synthesized hollow silver and iron oxide composite microspheres obtained by using silver nitrate solutions with different concentration.

$\left.\mathrm{S}_{14}\right), 3 \mathrm{M}_{\mathrm{Fe}}$ at $\left.0.002 \mathrm{M}_{\mathrm{AgN} 03}, \mathrm{~S}_{15}\right), 3 \mathrm{M}_{\mathrm{Fe}}$ at $0.006 \mathrm{M}_{\mathrm{AgN} 03}$,

$\left.\mathrm{S}_{16}\right), 3 \mathrm{M}_{\mathrm{Fe}}$ at $\left.0.01 \mathrm{M}_{\mathrm{AgN} 03}, \mathrm{~S}_{17}\right), 3 \mathrm{M}_{\mathrm{Fe}}$ at $0.02 \mathrm{M}_{\mathrm{AgN} 03}$.

More spherical particles with well defined morphologies were observed from the SEM images. This experiment was prepared by the co-precipitation method. TEM images confirm these spherical particles possess double shell hollow structure and even some triple-shell hollow structures also were observed from the TEM images. EDX results exhibited the presence of $\mathrm{Ag}$ in all the products and confirmed that we have successfully introduced sliver into hematite hollow microspheres. However, we should note that XRD results show that impurity $\mathrm{AgFeO}_{2}$ appeared in the resultant products when we used silver nitrate solutions with high concentration. That result possibly reflect the generation of bulk $\mathrm{Ag}$ particles $\left(\mathrm{AgFeO}_{2}\right)$, which is not desired. Therefore, we should carefully control the amount of silver precursor used in this process.

\section{Acknowledgment}

This study has been supported by a CASTWAS Postgraduate Fellowship in China. I am grateful to Professor Dan Wang, PhD. Xiaoyong Lai provided the necessary infrastructure to perform this research.

\section{Conclusions}

In summary, we have successfully prepared threetiple shell hollow silver and hematite 
composite microspheres $(\mathrm{Ag} / \alpha \mathrm{Fe} 2 \mathrm{O} 3)$ with $1.5 \mu \mathrm{m}$ diameter by various methods such as wet chemical, post-deposition and coprecipitation methods. The most suitable method was co-precipitation and the size of microshpere fibers was regularly produced by using this method. The effect of various experimental parameters on the morphologies and phase of the resultant products, such as the concentration (3M Fe(NO3)3, $0.01 \mathrm{M}$ $\mathrm{AgNO} 3)$ and the ratio of silver and iron ions $(\mathrm{Ag}: \mathrm{Fe}=1: 4,73)$ were investigated. And the size of the threetiple hollow spheres $(1.5 \pm 0.1$ $\mu \mathrm{m})$ is reduced to about $40 \%$ of the original size of template spheres $(2.45 \pm 0.2 \mu \mathrm{m})$ were established. The novel multiple shell hollow $\mathrm{Ag} / \alpha-\mathrm{Fe} 2 \mathrm{O} 3$ composite microspheres may find potential applications in catalysis, gas sensors, and so on.

\section{References}

1. Wash, D., Mann, S., Fabrication of hollow porous shells of calciumcarbonate self-organizing media. Nature 1995, 377, 320-323.; b) Wang, Q.; Li, H.; Chen, L. Q.; Huang, X. J. Carbon. 2001, 39, 2211-2214; (c) Wang, Q.; Li, H.; Chen, L. Q.; Huang, X. J. Solid State Ionics. 2002, 52-153, 43

2. Lou, X. W.; Archer, L. A.; Yang, Z. C., Hollow Micro-/Nanostructures: Synthesis and Applications. Adv. Mater. 2008, 20, 3987-4019.
3. Benabid, F.; Couny, F.; Knight, J. C.; Birks, T. A.; Russell, P. S., Compact, stable and efficient all-fibre gas cells using hollow-core photonic crystal fibres. Nature 2005, 434, 488-491.

4. An, K.; Hyeon, T., Synthesis and biomedical applications of hollow nanostructures. Nano Today 2009, 4, 359-373.

5. Yang, J.; Lee, J.; Kang, J.; Lee, K.; Suh, J. S.; Yoon, H. G.; Huh, Y. M.; Haam, S., Hollow silica nanocontainers as drug delivery vehicles. Langmuir 2008, 24, 34173421.

6. Wei, W.; Ma, G.-H.; Hu, G.; Yu, D.; McLeish, T.; Su, Z.-G.; Shen, Z.-Y., Preparation of Hierarchical Hollow $\mathrm{CaCO} 3$ Particles and the Application as Anticancer Drug Carrier. J. Am. Chem. Soc. 2008, 130, 15808-15810

7. Yang, M.; Ma, J.; Zhang, C. L.; Yang, Z. Z.; Lu, Y. F., General synthetic route toward functional hollow spheres with double-shelled structures. Angew. Chem. Int. Edit. 2005, 44, 6727-6730. Yang, M.; Ma, J.; Niu, Z.; Dong, X.; Xu, H.; Meng, Z.; Jin, Z.; Lu, Y.; Hu, Z.; Yang, Z., Synthesis of Spheres with Complex Structures Using Hollow Latex Cages as Templates. Adv. Funct. Mater. 2005, $15,1523-1528$.

8. Lou, Xiong W.; Yuan, C.; Archer, Lynden A., Shell-by-Shell Synthesis of Tin Oxide Hollow Colloids with Nanoarchitectured Walls: Cavity Size Tuning and Functionalization. Small 2007, 3, 261-265 